\title{
Monitoring the use of nifurtimox-eflornithine combination therapy (NECT) in the treatment of second stage gambiense human African trypanosomiasis
}

\author{
This article was published in the following Dove Press journal: \\ Research and Reports in Tropical Medicine \\ 23 August 2012 \\ Number of times this article has been viewed
}

Jose R Franco'

Pere P Simarro'

Abdoulaye Diarra ${ }^{2}$

Jose A Ruiz-Postigo ${ }^{3}$

Mireille Samo'

Jean G Jannin'

'World Health Organization, Control of Neglected Tropical Diseases,

Innovative and Intensified Disease

Management, Geneva, Switzerland;

${ }^{2}$ World Health Organization, Regional

Office for Africa, Brazzaville,

Congo; ${ }^{3}$ World Health Organization,

Communicable Disease Control,

Control of Tropical Diseases and

Zoonoses Regional Office for the

Eastern Mediterranean, Cairo, Egypt
Correspondence: Jose Ramon Franco World Health Organization, Control of Neglected Tropical Diseases, I2II Geneva, Switzerland

Tel +4l $2279 \mid 33$ I3

Fax $+4|2279| 4777$

Email francoj@who.int
Abstract: After inclusion of the nifurtimox-eflornithine combination therapy (NECT) in the Model List of Essential Medicines for the treatment of second-stage gambiense human African trypanosomiasis (HAT), the World Health Organization, in collaboration with National Sleeping Sickness Control Programs and nongovernmental organizations set up a pharmacovigilance system to assess the safety and efficacy of NECT during its routine use. Data were collected for 1735 patients treated with NECT in nine disease endemic countries during 2010-2011. At least one adverse event (AE) was described in 1043 patients (60.1\%) and a total of 3060 $\mathrm{AE}$ were reported. Serious adverse events (SAE) were reported for 19 patients ( $1.1 \%$ of treated), leading to nine deaths (case fatality rate of $0.5 \%$ ). The most frequent $\mathrm{AE}$ were gastrointestinal disorders (vomiting/nausea and abdominal pain), followed by headache, musculoskeletal pains, and vertigo. The most frequent SAE and cause of death were convulsions, fever, and coma that were considered as reactive encephalopathy. Two hundred and sixty-two children below 15 years old were treated. The characteristics of AE were similar to adults, but the major AE were less frequent in children with only one SAE and no deaths registered in this group. Gastrointestinal problems (vomiting and abdominal pain) were more frequent than in adults, but musculoskeletal pains, vertigo, asthenia, neuropsychiatric troubles (headaches, seizures, tremors, hallucinations, insomnia) were less frequent in children. Patient follow-up after treatment is continuing, but initial data could suggest that NECT is effective as only a low number of relapses have so far been reported (19 cases). However, additional monitoring is required to assess the efficacy of the treatment, particularly in children. NECT has given satisfactory results of safety in the usual conditions where HAT patients are managed and it is currently the best option for treatment of second stage of gambiense HAT.

Keywords: human African trypanosomiasis, sleeping sickness, T. b. gambiense, nifurtimox, eflornithine, pharmacovigilance

\section{Introduction}

Human African trypanosomiasis (HAT) (sleeping sickness) is a neglected tropical disease considered as lethal without treatment. It is found in sub-Saharan countries with a patchy distribution in foci. ${ }^{1}$ Many of these foci are in remote rural areas with difficult access to health services, such that treatment of HAT patients often relies on limited human and material resources. ${ }^{2}$

Most of the medicines used for the treatment of HAT are cumbersome to use and have a non-negligible toxicity. ${ }^{3}$ Choice of medicine depends on the form (HAT due to infection with Trypanosoma brucei gambiense or with T. b. rhodesiense) and stage of 
disease: early or first stage, with presence of trypanosomes in lymph, blood, and peripheral organs, or late or second stage, characterized by trypanosomes invading the central nervous system (CNS). ${ }^{4}$

For second-stage gambiense HAT, available medicines are melarsoprol (a toxic arsenical derivative) and eflornithine (less toxic but complicated to use). ${ }^{5}$ In March 2009, however, the World Health Organization (WHO) Expert Committee on the Selection and Use of Essential Medicines recommended inclusion of nifurtimox in combination with eflornithine in the Model List of Essential Medicines (EML), to be used for treatment of second stage of $T$. $b$. gambiense infection. ${ }^{6}$ This decision was mainly supported by results from a multicenter clinical trial comparing eflornithine monotherapy with the nifurtimox-eflornithine combination treatment (NECT) $;^{7,8}$ this trial concluded that the NECT combination had comparable safety and efficacy with eflornithine monotherapy but improved treatment feasibility, ${ }^{8}$ reducing the costs and the logistic difficulties. The eflornithine in monotherapy is administered at the daily dose of $400 \mathrm{mg} / \mathrm{kg}$ in slow infusion every 6 hours for 14 days for a total of 56 infusions, meanwhile eflornithine in NECT is used at the same dose but with slow infusions every 12 hours for 7 days, for a total of 14 infusions, combined with nifurtimox orally at the daily dose of $15 \mathrm{mg} / \mathrm{kg}$, three times a day for 10 days.

NECT has since been adopted as first-line treatment for second-stage gambiense HAT in the majority of endemic countries. ${ }^{9}$ The nifurtimox and eflornithine are donated to WHO through a Public-Private-Partnership by the pharmaceutical companies, Sanofi and Bayer, and are then supplied free-of-charge by WHO as a medical kit that includes basic material needed for administration of the combination treatment. WHO has also organized training of key staff in the use of NECT.

By $2010,59 \%$ of reported new cases of second-stage gambiense HAT were treated with $\mathrm{NECT}^{10}$ and the proportion of cases treated with NECT has since been increasing. Considering the short experience in the use of this combination, however, and in accordance with the Committee on the Selection and Use of Essential Medicines, WHO took the responsibility to set up a pharmacovigilance system in collaboration with Sleeping Sickness National Control Programs (SSNCP) and non-governmental organizations (NGOs).

\section{Methods}

In 2010, an active pharmacovigilance system for assessing the safety and efficacy of NECT in routine use was set up through WHO. The system was based on the collection and analysis of NECT safety and efficacy in regular use in different settings. Safety is assessed from characterization of adverse events (AE) during treatment, and efficacy assessed from the register of relapses in patients during the 2 years following treatment. For the pharmacovigilance of safety, simplified forms (see Appendix) were developed by expert consensus and validated with a group of the users. The qualifications of health staff in charge of HAT case management, the limited resources, the isolation, and difficulties in communication of the centers treating the cases were considered as well as the attempt to avoid overload of work.

The forms were filled for each patient presenting any adverse event during the treatment with NECT by the professional in charge of the patient (medical officer, clinical officer, or nurse) and sent quarterly straight to WHO or through the SSNCP.

Adverse events were considered as any undesirable sign, symptom, or medical condition occurring at the same time as treatment with NECT, which may or may not have been causally related. A major AE was defined when the intensity of the event was described as severe, very severe, or lethal, by the reporter, and a serious adverse event (SAE) was considered as any event that was fatal, life-threatening, permanently or significantly disabling, or that required or prolonged hospitalization, or caused a congenital anomaly. ${ }^{11}$

Training in pharmacovigilance and the use of the report forms was included during the guidance sessions for staff of disease endemic countries in the use of the NECT kit. The report forms were provided to the centers implementing NECT and all forms received by WHO from January 2010 to January 2012 were included in the present analysis.

The AE referred were listed and classified according to the common toxicity criteria for adverse events (CTCAE; version 4), of the National Cancer Institute (NCI). ${ }^{12}$

Information from the report forms was compiled into a database built in Access Microsoft ${ }^{\circledR}$ software (IBM, Armonk, NY). For the safety data, the following variables were considered:

- Putative relationship between the AE and treatment graded by the health staff in charge of the treatment as: lack of relationship, unlikely relationship, possible relationship, probable relationship, or certain relationship.

- Intensity of the AE - graded over five levels: mild, moderate, severe, very severe, and lethal, following the criteria referred in the CTCAE/v 4/NCI. ${ }^{12}$ 
- Action taken to mitigate the AE-noted as: NECT continued, temporarily suspended, or stopped definitively.

- Outcome of the AE - as completely disappeared, still present at the end of NECT, or if there were any sequelae or lethal outcome.

Treatment efficacy was assessed from the frequency of relapses, according to the criteria of the SSNCPs and WHO recommendations. A patient is considered cured when during a follow-up period of 24 months after treatment, no trypanosomes were detected and when the CSF returned to normal. ${ }^{13}$

As required by current regulation in pharmacovigilance, these data have been communicated to the manufacturers. Ethical approval was not required because this study is limited to analyzing data that were collected within the standard medical data recording and did not involve any experimental intervention. Treatment and patient management were all part of the routine activities of the SSNCP. The anonymity of the patients has been always maintained and the identification of the patients has never been available for authors.

\section{Results}

This analysis includes all the data reported to WHO from January 1, 2010 to January 31, 2012. Twenty-two sites in nine countries reported information (Table 1). Pharmacovigilance forms were filled in by medical officers (76\%), medical assistants (1\%), and nurses (22\%), although in $1 \%$ of the cases it was not described who filled in the form. Of the 1735 cases treated, 1043 patients (60.1\%) reported AE during NECT.

\section{Safety: analysis of $A E$}

There were 3060 AE reported, with an average of 2.9 events for each patient reporting any $\mathrm{AE}$. The $\mathrm{AE}$ were classified and grouped as 83 different AE according to CTCAE/v 4/NCI (Table 2). ${ }^{12}$

The most frequent adverse events were related to gastrointestinal disorders, followed by neuropsychiatric disorders. The most common were vomiting, headache, gastrointestinal pain, nausea, abdominal pain, vertigo, and anorexia. Other infections were uncommon.

\section{Safety: relationship with treatment}

Of the total AE reported, 2794 (91\%) were considered as having a possible, probable, or clear relationship with the treatment (Table 2), while the remainder (9\%) were considered to be unrelated to the treatment.

Table I Centers reporting NECT pharmacovigilance data

\begin{tabular}{|c|c|c|c|}
\hline Country & Treatment center & Cases treated with NECT & Patients with AE \\
\hline Central African & Hôpital Sous-préfectoral Batangafo & $234(13.5 \%)$ & $152(14.5 \%)$ \\
\hline Republic (CAR) & Hôpital Maitikoulou & $30(1.7 \%)$ & $21(2.0 \%)$ \\
\hline \multirow[t]{2}{*}{ Chad } & Hôpital Moissala & $23(1.3 \%)$ & $3(0.3 \%)$ \\
\hline & Centre de Santé Bodo Est & $13 \mid(7.5 \%)$ & $76(7.3 \%)$ \\
\hline Democratic Republic & Hôpital, Roi Baudouin, Kinshasa & $60(3.6 \%)$ & $31(3.0 \%)$ \\
\hline \multirow[t]{6}{*}{ of Congo (DRC) } & HGR (Hôpital General de Reference) de Doruma & $378(21.8 \%)$ & $236(22.6 \%)$ \\
\hline & HGR de Dingila & $538(31.0 \%)$ & $450(43.1 \%)$ \\
\hline & CDTC (Centre de Dépistage, Traitement et Contrôle) & $20(1.1 \%)$ & $2(0.2 \%)$ \\
\hline & de Katanda & & \\
\hline & CRT (Centre de Référence et de Traitement) & $40(2.3 \%)$ & $2(0.2 \%)$ \\
\hline & de Dipumba & & \\
\hline Equatorial Guinea & Hospital Regional de Bata & $12(0.7 \%)$ & $8(0.8 \%)$ \\
\hline \multirow[t]{5}{*}{ South Sudan } & Juba Teaching Hospital & $7(0.4 \%)$ & $\mathrm{I}(0.1 \%)$ \\
\hline & Yei Civil Hospital & $72(4.1 \%)$ & $23(2.2 \%)$ \\
\hline & Lui Hospital & $38(2.2 \%)$ & $10(1.0 \%)$ \\
\hline & Nimule Hospital & $14(0.8 \%)$ & $6(0.6 \%)$ \\
\hline & Yambio Hospital & $27(1.6 \%)$ & $2(0.2 \%)$ \\
\hline \multirow[t]{4}{*}{ Uganda } & Adjumani District Hospital & $13(0.7 \%)$ & $3(0.3 \%)$ \\
\hline & Omugo Health Center & $47(2.7 \%)$ & II (I.0\%) \\
\hline & Yumbe District Hospital & $12(0.7 \%)$ & $\mathrm{I}(0.1 \%)$ \\
\hline & Moyo District Hospital & $23(1.3 \%)$ & $0(0.0 \%)$ \\
\hline Cote d'lvoire & PRCT Daloa & $3(0.2 \%)$ & I (0.1\%) \\
\hline Congo & Hôpital Ngabe & $3(0.2 \%)$ & $2(0.2 \%)$ \\
\hline Guinea & Hypnoserie Dubreka & $10(0.6 \%)$ & $2(0.2 \%)$ \\
\hline Total & & 1735 & 1043 \\
\hline
\end{tabular}

Abbreviations: AE, adverse events; NECT, nifurtimox-eflornithine combination therapy. 
Table 2 Total adverse events reported (according to CTCAE classification)

\begin{tabular}{|c|c|c|c|c|c|c|}
\hline \multirow[t]{2}{*}{$\mathbf{A E}$} & \multicolumn{2}{|l|}{ Total } & \multicolumn{2}{|c|}{$\begin{array}{l}\text { Adults } \\
(\geq 15 \text { years) }\end{array}$} & \multicolumn{2}{|c|}{$\begin{array}{l}\text { Children } \\
\text { ( }<15 \text { years) }\end{array}$} \\
\hline & Total & $\begin{array}{l}\text { Related } \\
\text { to NECT }\end{array}$ & Total & $\begin{array}{l}\text { Related } \\
\text { to NECT }\end{array}$ & Total & $\begin{array}{l}\text { Related } \\
\text { to NECT }\end{array}$ \\
\hline Gastrointestinal disorders & 1214 & 1138 & 1017 & 955 & 196 & 183 \\
\hline Vomiting & 429 & 413 & 339 & 327 & 90 & 86 \\
\hline Gastrointestinal pain & 242 & 239 & 228 & 226 & 14 & 13 \\
\hline Nausea & 214 & 212 & 179 & 178 & 35 & 34 \\
\hline Abdominal pain & 201 & 171 & 158 & 134 & 42 & 37 \\
\hline Diarrhea (including dysentery) & 100 & 82 & 88 & 71 & 12 & 11 \\
\hline Others & 28 & 21 & 25 & 19 & 3 & 2 \\
\hline Nervous system disorders & 522 & 474 & 478 & 439 & 40 & 32 \\
\hline Headache & 308 & 271 & 281 & 249 & 25 & 21 \\
\hline Seizure & 106 & 102 & 100 & 97 & 6 & 5 \\
\hline Tremor & 68 & 63 & 65 & 61 & 3 & 2 \\
\hline Others & 40 & 38 & 32 & 32 & 6 & 4 \\
\hline General disorders & 257 & 212 & 220 & 189 & 34 & 21 \\
\hline Fatigue, asthenia, malaise & 121 & 121 & 115 & 115 & 5 & 5 \\
\hline Fever & 94 & 53 & 69 & 41 & 25 & 12 \\
\hline Others & 42 & 38 & 36 & 33 & 4 & 4 \\
\hline Musculoskeletal and connective tissue disorders & 245 & 205 & 232 & 199 & 12 & 6 \\
\hline Back pain & 100 & 81 & 91 & 78 & 9 & 3 \\
\hline Neck pain & 77 & 68 & 75 & 66 & 2 & 2 \\
\hline Others & 68 & 56 & 66 & 55 & 1 & I \\
\hline Psychiatric disorders & 242 & 233 & 228 & 222 & 10 & 9 \\
\hline Insomnia & 102 & 101 & 101 & 100 & 1 & 1 \\
\hline Agitation, anxiety & 48 & 42 & 39 & 35 & 7 & 6 \\
\hline Others & 92 & 90 & 88 & 87 & 2 & 2 \\
\hline Ear and labyrinth disorders & 201 & 199 & 195 & 195 & 6 & 4 \\
\hline Vertigo/dizziness & 190 & 190 & 186 & 186 & 4 & 4 \\
\hline Others & 11 & 9 & 9 & 9 & 2 & 0 \\
\hline Metabolism and nutrition disorders & 166 & 165 & 140 & 139 & 26 & 26 \\
\hline Anorexia & 164 & 163 & 138 & 137 & 26 & 26 \\
\hline Others & 2 & 2 & 2 & 2 & 0 & 0 \\
\hline Skin and subcutaneous tissue disorders & 59 & 50 & 53 & 45 & 6 & 5 \\
\hline Pruritus & 50 & 44 & 46 & 41 & 4 & 3 \\
\hline Others & 9 & 6 & 7 & 4 & 2 & 2 \\
\hline Vascular disorders & 55 & 42 & 47 & 37 & 8 & 5 \\
\hline Respiratory, thoracic and mediastinal disorders & 31 & 23 & 21 & 15 & 9 & 7 \\
\hline Infections and infestations & 19 & 10 & 15 & 8 & 4 & 2 \\
\hline Eye disorders & 19 & 17 & 18 & 16 & 1 & 1 \\
\hline Renal and urinary disorders & 14 & 12 & 13 & 12 & 0 & 0 \\
\hline Cardiac disorders & 12 & 12 & 12 & 12 & 0 & 0 \\
\hline Blood and lymphatic system disorders & 4 & 2 & 3 & 2 & I & 0 \\
\hline Total & 3060 & 2794 & 2692 & 2485 & 353 & 301 \\
\hline
\end{tabular}

Abbreviations: CTCAE, common toxicity criteria for adverse events; NECT, nifurtimox-eflornithine combination therapy.

\section{Safety: outcome of the $A E$ and actions taken to mitigate the $\mathrm{AE}$}

The majority of the patients with AE (82.4\%) recovered completely before the end of the treatment. One hundred and seventy-one patients (16.4\%) had AE still present at the end of treatment, three patients $(0.3 \%)$ remained with sequelae, and nine $(0.9 \%)$ died during treatment.

Vertigo (55 patients), fatigue, asthenia, or malaise (52 patients), anorexia (33 patients), headaches (19 patients), gastrointestinal pain (15 patients), tremor (12 patients), vomiting (10 patients), nausea ( 9 patients), abdominal pain ( 9 patients), pruritus ( 8 patients), and seizure ( 8 patients) were the $\mathrm{AE}$ that more often were still present after treatment. Fifty point five percent of patients having vertigo during treatment and $43.0 \%$ having asthenia remained with these symptoms at the end of treatment.

Out of the 1043 patients presenting any $\mathrm{AE}$, treatment had to be suspended temporarily due to an AE in 30 patients 
$(2.9 \%)$ and in 12 cases $(1.1 \%)$ had to be definitely stopped for the same reason.

\section{Safety: intensity of AE, serious AE, lethality}

Of the 1735 patients treated with NECT, 202 individuals presented a major AE: 189 individuals (10.9\%) had a severe AE, and $23(1.3 \%)$ had very severe or fatal events. The majority of AE were mild or moderate (90.5\%) but there were 290 major AE recorded, of which 262 (90\%) were considered as having a possible, probable, or clear relationship with treatment. The most frequent major $\mathrm{AE}$ were vomiting, seizures, nausea, vertigo, headache, and agitation/anxiety.

A total of $36 \mathrm{SAE}$ were reported in 19 patients $(1.1 \%$ of treated patients), leading to death in nine patients. Convulsions (eight patients), fever (seven patients), and coma (six patients) were the most frequent SAE (Table 3). In 11 of these 19 patients, the SAE were consistent with the concept of reactive encephalopathy, or encephalopathic syndrome (rate of reactive encephalopathy of $0.63 \%$ ), which is defined as a life-threatening event taking place during treatment for HAT, and characterized by a sudden deterioration of neurological status with either convulsions, progressive coma or psychotic reactions, or abnormal behavior. ${ }^{14}$ Of the nine deaths occurring during treatment $(0.52 \%$ case fatality rate), five were compatible with the clinical signs of reactive encephalopathy (high fever, coma, and convulsions) and can be assumed to be related to the treatment. The other four deaths were due to causes considered as not related to treatment: two probably related to sleeping sickness, one to severe anemia, and one to an acute abdomen (Table 3).

\section{Safety: data in children}

There are no data on the safety and efficacy in the use of NECT in children as the clinical trial was limited to individuals above 14 years old. ${ }^{78}$ Nevertheless, eflornithine for HAT and nifurtimox for Chagas disease have been largely used in children, and even nifurtimox has showed a safer profile in children. ${ }^{15}$

Amongst the 262 children below 15 years included in this dataset, $\mathrm{AE}$ were as frequent as in adults $\left(\chi^{2}=0.075\right.$, $P>0.5$ ) (Table 4). Three hundred and fifty-three AE were reported in 155 of these children (59.2\% of those treated, with an average of $2.3 \mathrm{AE}$ per case). Three hundred and one $\mathrm{AE}$ $(85.3 \%)$ were considered as possibly, probably, or certainly related to the NECT.

The most frequent $\mathrm{AE}$ in children were gastrointestinal (vomiting, nausea, and abdominal pain), nervous system disorders (headache), general troubles (fever), and anorexia. The gastrointestinal problems (vomiting and abdominal pain) were more frequent in children than in adults $\left(\chi^{2}=7.23, P<0.001\right)$, but the musculoskeletal pains

Table 3 Patients with serious adverse events reported

\begin{tabular}{|c|c|c|c|c|}
\hline No & Event & $\begin{array}{l}\text { Considered related } \\
\text { to NECT }\end{array}$ & Death & $\begin{array}{l}\text { Compatible with reactive } \\
\text { encephalopathy? }\end{array}$ \\
\hline I & $\begin{array}{l}\text { Depressed level of consciousness } \\
\text { with fever and death }\end{array}$ & No & Yes & No \\
\hline 2 & Coma with seizures and death & Yes & Yes & Yes \\
\hline 3 & Coma with seizures and fever & Yes & No & Yes \\
\hline 4 & $\begin{array}{l}\text { Coma with hypotension, seizures, } \\
\text { fever, and death }\end{array}$ & Yes & Yes & Yes \\
\hline 5 & Ataxia and urinary retention & Yes & No & No \\
\hline 6 & Psychotic reaction & Yes & No & No \\
\hline 7 & High fever and death & No & Yes & No \\
\hline 8 & High fever and death & Yes & Yes & Yes \\
\hline 9 & $\begin{array}{l}\text { Agitation, abnormal behavior, } \\
\text { fever, and encephalopathy }\end{array}$ & Yes & No & Yes \\
\hline 10 & Severe anemia and death & No & Yes & No \\
\hline II & Fever and seizures & Yes & No & Yes \\
\hline 12 & Fever, seizures, coma, and death & Yes & Yes & Yes \\
\hline 13 & Repeated seizures & Yes & No & Yes \\
\hline 14 & Severe dyspnea & Yes & No & No \\
\hline 15 & Seizure and encephalopathy & Yes & No & Yes \\
\hline 16 & Paralysis & Yes & No & No \\
\hline 17 & Seizure, confusion, paralysis & Yes & No & Yes \\
\hline 18 & Acute abdomen and death & No & Yes & No \\
\hline 19 & Confusion, coma, and death & Yes & Yes & Yes \\
\hline
\end{tabular}

Abbreviation: NECT, nifurtimox-eflornithine combination therapy. 
Table 4 Distribution of cases treated and presenting AE according to age group

\begin{tabular}{lll}
\hline Age & Cases treated & Patients with AE \\
\hline $0-4$ years & $40(2.3 \%)$ & $26(2.5 \%)$ \\
$5-14$ years & $222(12.8 \%)$ & $129(12.4 \%)$ \\
$>14$ years & $1452(83.7 \%)$ & $876(84.0 \%)$ \\
NA & $21(1.2 \%)$ & $12(1.1 \%)$ \\
Total & 1735 & 1043 \\
\hline
\end{tabular}

Abbreviations: $\mathrm{AE}$, adverse events; NA, not available.

$\left(\chi^{2}=25.6, P<0.001\right)$, vertigo $\left(\chi^{2}=28.9, P<0.001\right)$, asthenia $\left(\chi^{2}=13.1, P<0.001\right)$, nervous system (headaches, seizures, tremors) $\left(\chi^{2}=41.3, P>0.001\right)$, and psychiatric disorders (hallucinations, insomnia) $\left(\chi^{2}=28.5, P<0.001\right)$ were relatively more frequent in adults (Table 2 ).

There were 26 major AE registered in 19 children ( $7.2 \%$ of all children treated), with the most frequent being vomiting and nausea, and agitation/anxiety. Only one SAE was reported in a child (a case of paralysis with sequelae), but no reactive encephalopathy or death was registered in children.

There was no difference in the analysis of data for children below 5 years. Twenty-six children $(65.0 \%)$ of this group presented $\mathrm{AE}$, in a proportion not significantly higher than the rest of patients $\left(\chi^{2}=0.401, P>0.5\right)$. Sixty-four $\mathrm{AE}$ were reported in this group and the most frequent were vomiting, fever, nausea, anorexia, and abdominal pain. Fever was significantly more frequent in small children than in the rest $\left(\chi^{2}=16.98, P<0.001\right)$. Seven of the AE in five children were considered as major and none as a SAE.

\section{Efficacy: analysis of relapses}

So far, 19 relapses have been reported after NECT, from six different treatment centers. These were detected between 5 to 13 months after treatment (average 8.6 months).

Although patient follow-up after HAT treatment can be limited, ${ }^{16-19}$ it is often seen that relapsing patients do tend to come for assessment because of their clinical symptoms. ${ }^{20}$ Cautiously therefore, the data can be taken to indicate the apparent rate of relapse: 551 cases have completed at least 1 year after finishing the treatment, and during this time, ten relapses have been reported - a relapse rate of $1.8 \%$ at 1 year after treatment.

There were six relapses (32\%) reported in children below 15 years with an estimated relapse rate at 1 year of 3.6\%. These data could suggest a minor efficacy in children but it is not statistically significant and more completed data are needed.

\section{Discussion: comparison with previous data}

Previous data about the use of NECT derived primarily from a clinical trial comparing NECT and eflornithine in the treatment of second-stage gambiense HAT. ${ }^{8}$ Other series of cases treated with NECT were short and used different schemas. ${ }^{21,22}$ During the referred clinical trial, a limited number of patients (143) received NECT subject to specified criteria for inclusion in the study. Treated patients were in hospital under daily supervision during treatment and for at least 1 week afterwards. By contrast, the current dataset derives from treatment taking place in the normal routine of treatment centers, including all the cases in second stage, as for instance patients with serious health conditions or patients with 6-20 leukocytes per $\mu \mathrm{L}$ in the cerebrospinal fluid, that were not included in the clinical trial.

In the clinical trial, reports of adverse events took into account all the biological and clinical events occurring during treatment, whereas from the routine treatment system described here, the AE were reported just on the basis of clinical manifestations. As expected therefore, the frequency of $\mathrm{AE}$ registered in the clinical trial was higher (94\% of patients treated), but data about major clinical AE, SAE, and deaths during treatment, are similar (Table 5).

The most frequent $\mathrm{AE}$ in both datasets included vomiting, nausea, headache, musculoskeletal pain, abdominal pain, and anorexia. Patients affected by vomiting and nausea, tremors, and hallucination, also had the same frequency in both studies. The number of patients reported with fever, seizures, other infections, and cardiovascular events was higher in the clinical trial, but lower for those with abdominal pain.

Previous first-line treatment for second-stage HAT gambiense was eflornithine in monotherapy. Compared to this treatment, ${ }^{9,18,23}$ the NECT has shown fewer serious adverse events and fewer deaths (Table 5), which may reflect reduced drug-related toxicity due to the shorter eflornithine regimen. ${ }^{24}$

Since April 2009, the Drug Neglected Diseases Initiative (DNDi) has sponsored a further clinical trial (NECT Field) of the feasibility, safety, and efficacy of NECT in second stage cases of gambiense sleeping sickness in DRC (hospitals of Bandundu, Dipumba, Katanda, Kwamouth, Ngandajika, Yasa Bonga). Six hundred and twenty-nine patients have been included in the study and treated with NECT. Thirty-nine SAE have so far been reported in 32 patients, with ten deaths during treatment (O Valverde, personal communication). ${ }^{25}$ This study has a close active follow-up of the patients, and 
Table 5 Comparison of eflornithine monotherapy treatment (in the NECT clinical trial, ${ }^{7,8}$ and during routine use in the lbba MSF treatment Centre, South Sudan), ${ }^{20}$ and NECT (in the NECT clinical trial ${ }^{7,8}$ and in routine use as monitored by WHO)

\begin{tabular}{|c|c|c|c|c|c|c|c|c|}
\hline & \multicolumn{4}{|c|}{ Eflornithine } & \multicolumn{4}{|c|}{ NECT } \\
\hline & \multicolumn{2}{|c|}{ NECT clinical trial } & \multicolumn{2}{|c|}{$\begin{array}{l}\text { Control program } \\
\text { Ibba (S. Sudan) }\end{array}$} & \multicolumn{2}{|c|}{ NECT clinical trial } & \multicolumn{2}{|c|}{$\begin{array}{l}\text { Routine use } \\
\text { PV system }\end{array}$} \\
\hline & $\mathbf{n}$ & $\%$ & $\mathbf{n}$ & $\%$ & $\mathbf{n}$ & $\%$ & $\mathbf{n}$ & $\%$ \\
\hline Cases treated $(n)$ & 143 & & 1055 & & 143 & & 1735 & \\
\hline Cases with at least one $A E$ & 134 & 93.7 & 962 & 91.2 & 134 & 93.7 & 1043 & 60.1 \\
\hline Cases with major clinical $\mathrm{AE}$ & 33 & 23.1 & 138 & 13.1 & 18 & 12.6 & 189 & 10.9 \\
\hline Cases with SAE & 6 & 4.2 & & & 1 & 0.7 & 19 & 1.1 \\
\hline Cases requiring treatment interruption & 9 & 6.3 & 109 & 10.3 & & & 45 & 2.6 \\
\hline Deaths during treatment & 3 & 2.1 & 16 & 1.5 & I & 0.7 & 9 & 0.5 \\
\hline
\end{tabular}

Abbreviations: AE, adverse event; MSF, Médecins Sans Frontières ; NECT, nifurtimox-eflornithine combination therapy; SAE, serious adverse event; WHO, World Health Organization.

should provide important further information mainly about the efficacy of the clinical use of NECT.

Nifurtimox has been used in monotherapy, mainly in the treatment of Chagas disease, showing a significant risk of AEs, mainly gastrointestinal (anorexia, nausea, abdominal pain, vomiting), neuropsychiatric (headache, insomnia, mood alteration), and fatigue. SAEs are also described and mainly related to allergic reactions (eosinophilia, rash, pruritus, edema, dyspnea). ${ }^{26}$ Nevertheless, the duration of treatment with nifurtimox is much longer in Chagas disease (60-120 days).

A limitation of pharmacovigilance data is the subjective component in the report of AEs and SAEs. In the present analysis, the heterogeneity between the different sites and the judgment of the different reporters is an added limitation. However, at the same time, this heterogeneity gives added value to the results as it includes different settings with different circumstances, making the situation closer to real life. Comparison with previous studies has to be cautiously considered as the conditions of the studies were not the same.

\section{Conclusion}

A simplified pharmacovigilance system has provided key information in the routine use of the NECT protocol for gambiense trypanosomiasis. In spite of the isolation and limited resources in most of the treatment centers, awareness of the importance and usefulness of the system has given a satisfactory reporting rate.

The reports from the routine use of NECT are consistent with the results of the original clinical trial. NECT generates a number of adverse events, mainly linked to gastrointestinal and neuropsychiatric problems. However, the severity of these events is relatively low compared to previous treat- ments, and the majority of patients treated make a good recovery.

Safety in children does not show important differences compared with adults but more complete data are needed.

For the moment, the data suggest the treatment to be effective against gambiense trypanosomiasis, since only a low number of relapses have been reported during the analysis period, and no critical problems in efficacy have been detected. However, further patient follow-up is required to provide a full measure of efficacy, stressing the collection of data in children.

With the data obtained so far and despite the frequent adverse events, it can be considered that use of NECT in second-stage gambiense sleeping sickness has given satisfactory safety results in the usual conditions where HAT patients are managed, and it is currently the best option for treating this disease.

\section{Acknowledgments}

We thank the health professionals from the national sleeping sickness control programs (Central African Republic, Chad, Cote d'Ivoire, Democratic Republic of Congo, Republic of Congo, Equatorial Guinea, Guinea, Republic of South Sudan, and Uganda) and NGOs (Médecins Sans Frontières, Merlin) for compiling the pharmacovigilance reports. Special thanks to Andrea Riedel, Apai Onesta, Beatrice Kola-Bongo, David Schrumpf, François Chappuis, Jose Amici, Emile Alirol, Fioboy Marcel, Cecilia Maracci, Eustaquio Nguema, Justin Rubena, Jane Pita, Nines Lima, Ble Sepe, Nsengi Ntamabyaliro, Elizeous Surur, Joseph Zahiri, Gabriel Giris, Repent Buba, Ariga Musa, Joseph A Idoru, Victor Kande, Peka Mallaye, Stephane Ngampo, and Olema Erphas for their work in collecting, filtering, and transferring the reports. 
We acknowledge the support of Sanofi in the analysis of data.

\section{Disclosure}

The authors report no conflicts of interest in this work. As stated in the paper, drugs used in the treatment of HAT are provided free of charge by Sanofi and Bayer.

\section{References}

1. Simarro PP, Cecchi G, Paone M, et al. The Atlas of human African trypanosomiasis: a contribution to global mapping of neglected tropical diseases. Int J Health Geogr. 2010;9:57.

2. Simarro PP, Jannin J, Cattand P. Eliminating human African trypanosomiasis: where do we stand and what comes next? PLoS Med. 2008;5:e55.

3. Barrett MP, Boykin DW, Brun R, Tidwell RR. Human African trypanosomiasis: pharmacological re-engagement with a neglected disease. $\mathrm{Br}$ J Pharmacol. 2007;152:1155-1171.

4. Burri C, Brun R. Human African trypanosomiasis. In: Cook GC, Zumla A, editors. Manson's Tropical Diseases. 21st ed. London, UK: Elsevier Science limited; 2003:1303-1323.

5. Burri C. Chemotherapy against human African trypanosomiasis: Is there a road of success? Parasitology. 2010;137:1987-1994.

6. World Health Organization. WHO model list of essential medicines, 16th list March 2009. Geneva, Switzerland: WHO; 2009. Available from: http://www.who.int/medicines/publications/essentialmedicines/ en/index.html. Accessed January 30, 2012.

7. Priotto G, Kasparian S, Ngouama D, et al. Nifurtimox-Eflornithine combination therapy for second-stage Trypanosoma brucei gambiense sleeping sickness: a randomized clinical trial in Congo. Clin Infect Dis. 2007;45:1435-1442.

8. Priotto G, Kasparian S, Mutombo W, et al. Nifurtimox-eflornithine combination therapy for second-stage African Trypanosoma brucei gambiense trypanosomiasis: a multicentre, randomised, phase III, non-inferiority trial. Lancet. 2009;374:56-64.

9. Who.int [homepage on the Internet]. World Health Organization: Human African trypanosomiasis. Symptoms, diagnosis and treatment. Available from: http://www.who.int/trypanosomiasis_african/diagnosis/en/index. html. Accessed April 30, 2012.

10. Simarro PP, Franco JR, Diarra A, Postigo JA, Jannin J. Update on field use of the available drugs for the chemotherapy of human African trypanosomiasis. Parasitology. 2012;139(7):842-846.

11. World Health Organization. Safety of Medicines - A Guide to Detecting and Reporting Adverse Drug Reactions - Why Health Professionals Need to Take Action. WHO/EDM/QSM/2002. Geneva, Switzerland: WHO; 2002.

12. Evs.nci.nih.gov [homepage on the Internet]. US Department of Health and human services, National Institutes of Health, National Cancer Institute. Common Terminology Criteria for Adverse Events (CTCAE). Version 4.01. Available from http://evs.nci.nih.gov/ftp1/CTCAE/About. html. Accessed January 30, 2012.
13. World Health Organization. Epidemiology and control of African trypanosomiasis. Report of a WHO Expert Committee. Technical Report Series 739. Geneva, Switzerland: WHO; 1986.

14. Blum J, Nkunku S, Burri C. Clinical description of encephalopathic syndromes and risk factors for their occurrence and outcome during melarsoprol treatment of human African trypanosomiasis. Trop Med Int Health. 2001;6(5):390-400.

15. Altcheh J, Biancardi M, Lapena A, Ballering G, Freilij H. Congenital Chagas disease: experience in the Hospital de Niños, Ricardo Gutiérrez, Buenos Aires, Argentina. Rev Soc Bras Med Trop. 2005;38 Suppl 2: 41-45. Spanish.

16. Ngampo S. Suivi post-thérapeutique des malades trypanosomés à T. b. gambiense: problèmes et perspectives. [post-therapeutical follow-up of T.b. gambiense: problems and perspectives]. Antwerp, Belgium: Instituut voor Tropische Geneeskunde; 1992. French.

17. Robays J, Lefort A, Lutumba P, et al. Drug toxicity and cost as barriers to community participation in HAT control in the Democratic Republic of Congo. Trop Med Int Health. 2007;12:290-298.

18. Miézan TW, Djé NN, Doua F, Boa F. Human African trypanosomiasis in Ivory Coast: biological characteristics after treatment. 812 cases treated in the Daloa focus (Ivory Coast). Bull Soc Pathol Exot Fil. 2002;95:362-365. French.

19. World Health Organization. Recommendations of the informal consultation on issues for clinical product development for human African trypanosomiasis. Geneva, Switzerland: WHO/CDS/NTD/IDM; 2007.

20. Priotto G, Pinoges L, Badi Fursa I, et al. Safety and effectiveness of first line eflornithine for Trypanosoma brucei gambiense sleeping sickness in Sudan: cohort study. BMJ. 2008;29:336:(7646):705-708.

21. Checchi F, Piola P, Ayikoru H, Thomas F, Legros D, Priotto G. Nifurtimox plus Eflornithine for late-stage sleeping sickness in Uganda: a case series. PloS Negl Trop Dis. 2007;1:e64.

22. Priotto G, Fogg C, Balasegaram M, et al. Three drug combinations for late-stage Trypanosoma brucei gambiense sleeping sickness: a randomized clinical trial in Uganda. PLoS Clin Trials. 2006;1:e39.

23. Priotto G. Eflornithine for first line-treatment of trypanosomiasis: assessment of safety and effectiveness. Ibba, South Sudan. Paris, France: Epicentre; 2003.

24. Pepin J, Khonde N, Maiso F, et al. Short course eflornithine in Gambian trypanosomiasis: a multicentre randomized controlled trial. Bull World Health Organ. 2000;78:1284-1295.

25. Valverde Mordt O, Schmid C, Kande V, et al. In-hospital safety of NECT use to treat 2nd stage T. b. gambiense in African children, pregnant and breast-feeding women. European Congress of Tropical Medicine and International Health; Barcelona, Spain; October 5, 2011.

26. Jackson Y, Alirol E, Getaz L, Wolff H, Combescure C, Chappuis F. Tolerance and safety of nifurtimox in patients with chronic chagas disease. Clin Infect Dis. 2010;51:e69-e75. 


\section{Appendix}

\section{Sleeping Sickness National Control Program \\ Pharmacovigilance for nifurtimox-eflornithine combina- tion treatment}

ADVERSE EVENTS DURING NIFURTIMOX-EFLORNITHINE COMBINATIONTREATMENT REPORT FORM

\begin{tabular}{|l|l|l}
\hline Country: & Year: & Treatment center: \\
\hline
\end{tabular}

\begin{tabular}{|l|l|l|l|}
\hline PATIENT INITIALS: & CODE: & AGE: & SEX: \\
\hline
\end{tabular}

Starting date Nifurtimox-Eflornithine combination treatment '

\begin{tabular}{|c|c|c|c|c|c|c|}
\hline $\begin{array}{c}\text { Description } \\
\text { of the adverse } \\
\text { event }\end{array}$ & $\begin{array}{c}\text { Starting date } \\
\text { of the adverse } \\
\text { event }\end{array}$ & $\begin{array}{c}\text { Duration } \\
\text { in days }\end{array}$ & $\begin{array}{l}\quad \text { Intensity } \\
\text { I. Mild } \\
\text { 2. Moderate } \\
\text { 3. Severe } \\
\text { 4. Life-threatening } \\
\text { 5. Death }\end{array}$ & $\begin{array}{l}\text { Relationship with } \\
\text { the treatment } \\
\text { I. Unrelated } \\
\text { 2. Unlikely } \\
\text { 3. Possible } \\
\text { 4. Probable } \\
\text { 5. Certain }\end{array}$ & $\begin{array}{l}\quad \text { Action } \\
\text { 0. Treatment continued } \\
\text { I. Treatment suspended } \\
\text { (temporary) } \\
\text { 2. Treatment stopped } \\
\text { (definite) }\end{array}$ & $\begin{array}{l}\quad \text { Outcome } \\
\text { 1. Complete recovery } \\
\text { 2. Still present } \\
\text { 3. Sequelae } \\
\text { 4. Death }\end{array}$ \\
\hline & 1 & & & & & \\
\hline & 11 & & & & & \\
\hline & $1 \quad 1$ & & & & & \\
\hline & 11 & & & & & \\
\hline & 1 & & & & & \\
\hline
\end{tabular}

\begin{tabular}{|c|c|c|c|}
\hline Other drugs used & Date started & Duration in days & $\begin{array}{l}\text { Indicate the underlying pathology for which the drug } \\
\text { was administered }\end{array}$ \\
\hline & 11 & & \\
\hline & 1 & & \\
\hline & 11 & & \\
\hline & 11 & & \\
\hline
\end{tabular}

Date: Reporter:

Qualification:

\section{Publish your work in this journal}

Research and Reports in Tropical Medicine is an international, peerreviewed, open access journal publishing original research, case reports, editorials, reviews and commentaries on all areas of tropical medicine, including: Diseases and medicine in tropical regions; Entomology; Epidemiology; Health economics issues; Infectious disease; Laboratory science and new technology in tropical medicine; Parasitology; Public health medicine/health care policy in tropical regions; and Microbiology. The manuscript management system is completely online and includes a very quick and fair peer-review system. Visit http://www.dovepress. com/testimonials.php to read real quotes from published authors. 